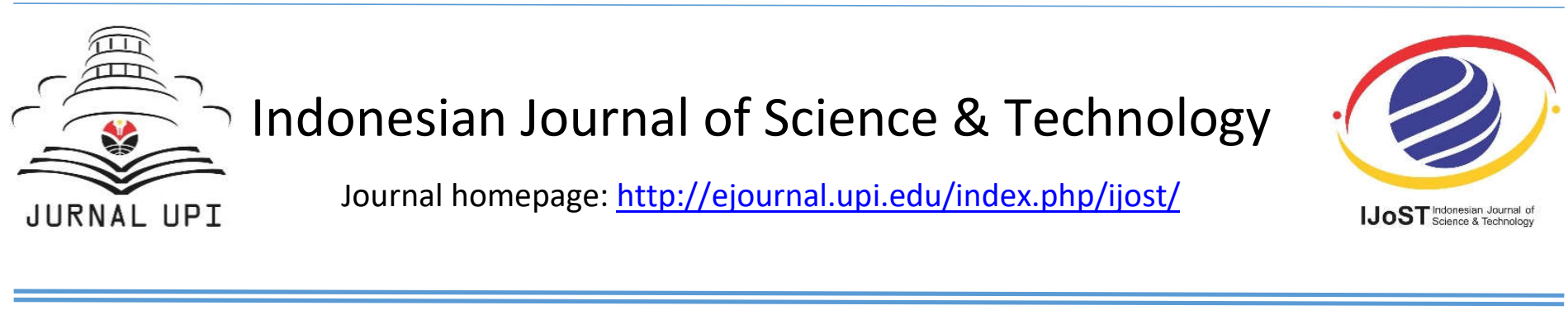

\title{
Use of Process Simulation for Plant Debottlenecking
}

Zulfan Adi Putra*

TMC Chemical, Flight Forum 107, NL-5657 DC Eindhoven, The Netherlands

*Corresponding author: Email: zulfan.adi.putra@tmc.nl

\begin{abstract}
A B STR A C T
This paper was aimed to illustrate the use of process simulation tools to find bottlenecks in a chemical plant. In practice, finding the first bottleneck of a plant is simply by increasing the capacity. However, two questions remain, e.g. what would the next bottleneck be and how big the first bottleneck needs to be expanded until the next bottleneck is reached. These questions can be repeated until eventually the whole equipment in the plant needs to be debottlenecked. Since it is impossible to answer the above questions in practice, a process simulation approach is utilized. Relevant equipment data and a validated thermodynamic model are used to build such a model. Plant performance trials are taken into account to estimate practical parameters such as fouling coefficients and plate tightness. This work requires strong interactions between operational people, consistent data gathering, and process simulation skill. The approach used in this work has shown that a reasonably accurate model can be built. The result has shown that the model can identify the first bottleneck as confirmed on the field. Sequence of bottlenecks and their corresponding increment of capacity increase have also been identified. The simulation results also illustrate the use of process simulation for plant debottlenecking.

(C) 2016 Tim Pengembang Journal UPI
\end{abstract}

\author{
ARTICLE INFO \\ Article History: \\ Submitted/Received 2 Jan 2016 \\ First Revised 18 Feb 2016 \\ Accepted 23 Feb 2016 \\ First Available online 29 Mar 2016 \\ Publication Date 01 Apr 2016
}

Keywords:

Aspen plus

Heat exchanger design

Sequential modular

Equation oriented

Process simulation

Plant debottlenecking 


\section{INTRODUCTION}

During its life time, a chemical process plant is typically debottlenecked several times. (Litzen \& Bravo, 1999) These debottlenecking projects could be due to various reasons such as increasing cost of raw materials or waste treatments, or even simply to increase plant capacity. (See http://www.icheme.org/icheme home/com munities/special-interest-

groups/safety\%20and\%20loss\%20preventio n/resources/ /media/Documents/Subject\% 20Groups/Safety Loss Prevention/WCCE/O 67-001.pdf)

In practice, the plant can simply be run with increasing capacity until it reaches its first bottleneck. (Pegels \& Watrous, 2005). Until this first bottleneck is relaxed, the next bottleneck(s) is (are) practically unknown. Thus, it is also practically not possible to doincremental debottlenecking without knowing how much it will gain. Hence, the use of process simulation tool can help identifying this sequence of bottlenecks. This present work is aimed to illustrate how process simulation tools can be utilized to solve such industrial problem.

Consider Figure 1 where a multiple effect evaporator plant of a chemical plant is evaluated. This plant is designed to produce $78 w t \%$ of sulfuric acid (remaining is water) from a dilute feed stream. The feed stream undergoes stream splitting via preheater 1 and preheater 2, and then subsequently sent to $1^{\text {st }}$ effect, preheater $3,2^{\text {nd }}$ effect, preheater $4,3^{\text {rd }}$ effect, and $4^{\text {th }}$ effect (forced circulation unit). Heat source for the $1^{\text {st }}$ effect comes from the evaporated water from the $2^{\text {nd }}$ effect. And heat source for the $2^{\text {nd }}$ effect comes from the $\mathbf{3}^{\text {rd }}$ effect. The $\mathbf{3}^{\text {rd }}$ effect itself is heated by a low pressure steam (LPS). The $4^{\text {th }}$ effect is heated by a high pressure steam (HPS). Preheater 3 is heated by the condensate of the LPS, while the prehater 4 is heated by the condensate of the HPS. Shell and tube heat exchangers are used in each effect, while plate and frame heat exchangers are used in the preheaters.

The current system has several constraints, such as product temperature, and the condensates should be below $40^{\circ} \mathrm{C}$ and maximum LPS supply is $5000 \mathrm{~kg} / \mathrm{h}$. It is decided to check what the current bottleneck is if either or both feed flowrate and sulfuric acid concentration is increased. If it is then debottlenecked, how much the capacity can be increased before the next bottleneck is reached. And these questions are then repeated.

It can be seen that the plant has multiple recycle streams and highly heat integrated. Typical process simulation software such as Aspen Plus has a default calculation mode of sequential modular. (See www.aspentech.com) This calculation mode is known for not so powerful in solving many recycle streams. Hence, solving the problem with this default mode is almost impractical, given the time constraint to complete the project. On the other hand, all of the heat exchangers need to be simultaneously checked to see if any of them becomes the bottleneck. (Biegler et al., 2002; Zhu \& Asante, 1999; Skogestad, 2004) This type of problem requires a different approaches as it will be outlined in this paper.

\section{SOLUTION APPROACH}

To overcome the above mentioned problem, the approach in Figure $\mathbf{2}$ is proposed. An Aspen Plus model is built and the calculation mode is changed to equation oriented mode. This mode of calculation takes the whole equations and solved them simultaneously instead of sequentially as in the default mode. Data from plant test run along with validated thermodynamic model 
are used to evaluate the current the required overall heat transfer peformance of the multiple effect plant. coefficients (U) and steam can be obtained. With varying feed flowrate and feed These trends are then plotted in a so-called concentration, and also considering the performance curves of the existing plant plant operating constraints, some trends on (Turton et.al., 2008).

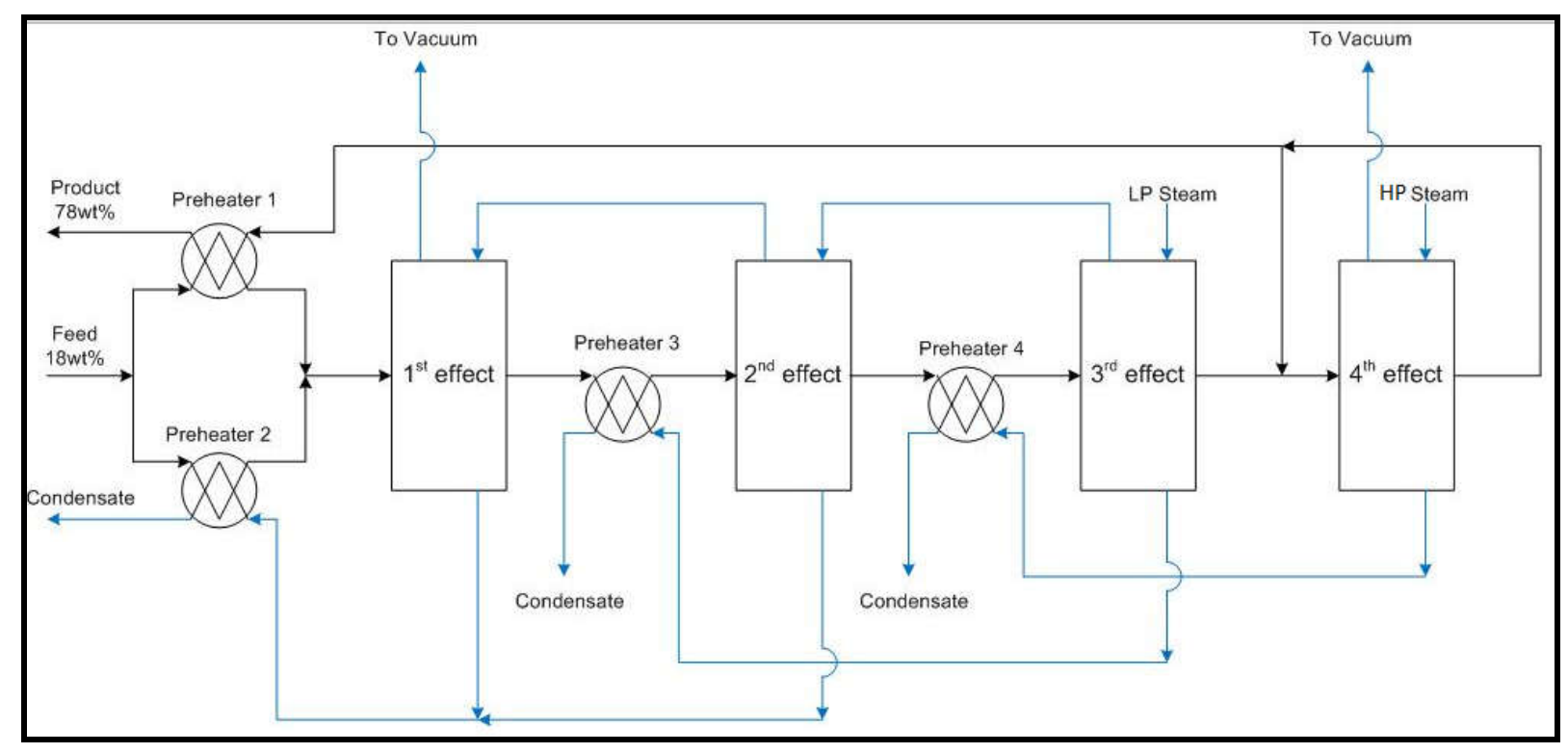

Figure 1. Process scheme for the multiple effect evaporator of a chemical plant

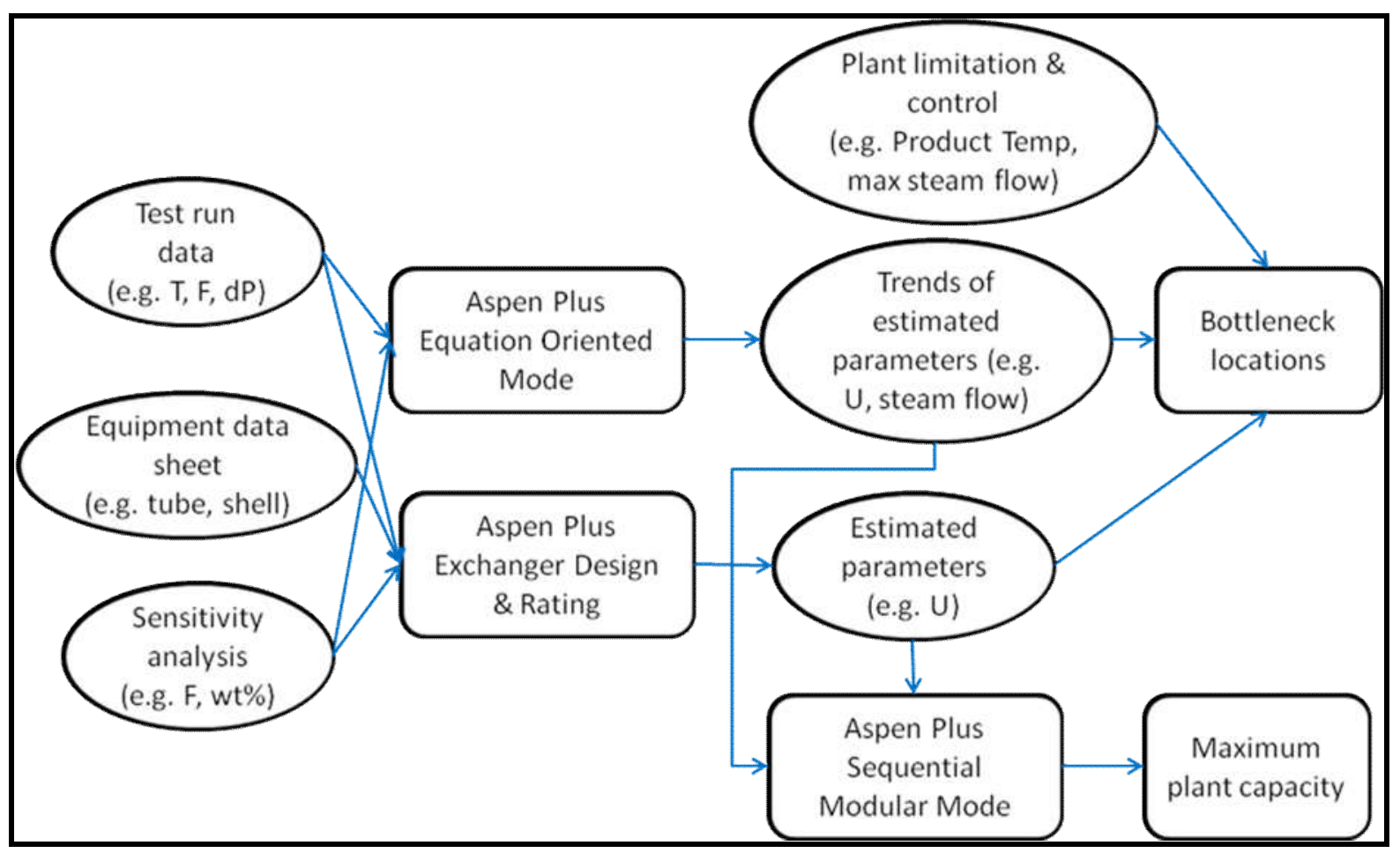

Figure 2. Process simulation approach for finding plant debottlenecks 
77 | Indonesian Journal of Science \& Technology, Volume 1 Issue 1, April 2016 Hal 74-81

This data from the plant test and equipment data are also used to evaluate the current performance of the heat exchangers. Performance parameters such as fouling conditions and how the plates are tightened are also estimated. These two parameters are useful in matching the overall heat transfer coefficients $(U)$ and the heat exchanger pressure drops. These parameters are optimized in a separate Aspen Plus Exchanger Design \& Rating (EDR) software (See www.aspentech.com). This calculation takes into account the datasheet of the exchangers. Later on, with varying feed flowrate and concentration, ranges of overall heat transfer coefficients can be obtained. The required $U$ values from the Aspen Plus model are then compared and checked in the Aspen Plus EDR to see if those values are acceptable. If the value is not acceptable, the corresponding heat exchanger is considered as the bottleneck.

The acceptable $U$ values are then used in the Aspen Plus model, with sequential modular mode of calculation, still considering current operational constraints, to obtain the maximum plant capacity.

\section{RESULTS AND DISCUSSION}

Figure 3 below shows the performance curves when both the sulfuric acid concentration in the feed is varied from $12 \mathrm{wt} \%$ (current) to $25 \mathrm{wt} \%$ and feed flowrate from 10000 (current) $\mathrm{kg} / \mathrm{hr}$ to $20000 \mathrm{~kg} / \mathrm{hr}$. In the figure, LPS $10000 \mathrm{~kg} / \mathrm{hr}$ means that it is the LPS consumption curve for 10000 $\mathrm{kg} / \mathrm{hr}$ of feed. Regarding the higher feed flowrate, it is obvious that the requirements of both LPS and HPS streams increase. However, when the feed concentration increases, two different situations are shown. By increasing the sulfuric acid concentration, the amount of LPS decreases due to lower amount of water to be evaporated in the 3rd effect. On the other hand, the HPS increases with higher sulfuric concentration in the feed, which then increases the amount of feed to the last 4th effect (forced circulation effect).

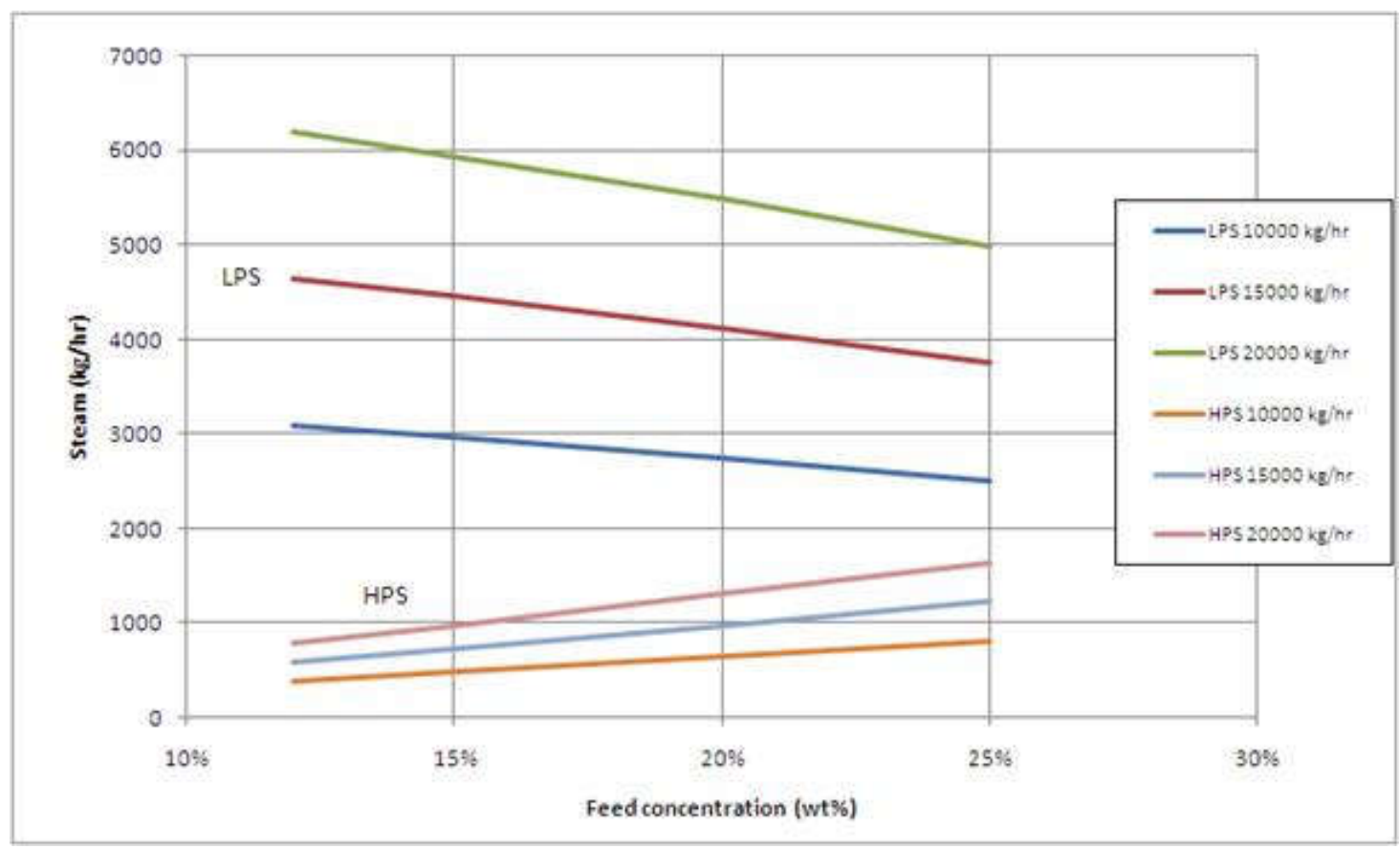

Figure 3. Performance curves of low pressure steam (LPS) and high pressure steam (HPS) requirement 
With the $5.000 \mathrm{~kg} / \mathrm{hr}$ limit on the LPS and current feed concentration of $12 \mathrm{wt} \%$, capacity can be increased until about 15.000 $\mathrm{kg} / \mathrm{hr}$. The plant will hit the LPS supply as the bottleneck. Nonetheless, if the feed concentration can be increased until above $25 w t \%$, LPS supply may not be the bottleneck anymore. This may also mean that the upstream concentration unit will have to work harder.

Figure 4 below shows the required overall heat transfer coefficient (U) for the 1st, 2nd, and 3rd effect, as well as the forced circulation exchangers. Separate simulations with Aspen Plus EDR show that the $U$ values on these heat exchangers (shell $\&$ tube type) are in the range of $600-800$ $\mathrm{W} /(\mathrm{m} 2 . \mathrm{K})$. It can be seen that the $2 \mathrm{nd}$ and the 3rd effects can handle feed with higher concentrations. On the other hand, the 1st effect requires much higher $U$ values to do its required work at $15.000 \mathrm{~kg} / \mathrm{h}$ of feed at the current concentration. Hence, it is the bottleneck at that point. This is due to its smaller heat exchanger area compared to the other effects, while at this feed condition, the evaporated water from the 2 nd effect is quite high.

The opposite situation happens with the 4th effect (forced circulation unit). Increasing the feed concentration will increase the required $U$ value to impractical values. The reason has been discussed above that the feed to this effect increases due to the higher absolute amount of sulfuric acid in the feed. Hence, this 4th effect (forced circulation) may be the bottleneck if the feed concentration increases to $20 \mathrm{wt} \%$ at the current feed flowrate of $10.000 \mathrm{~kg} / \mathrm{hr}$.

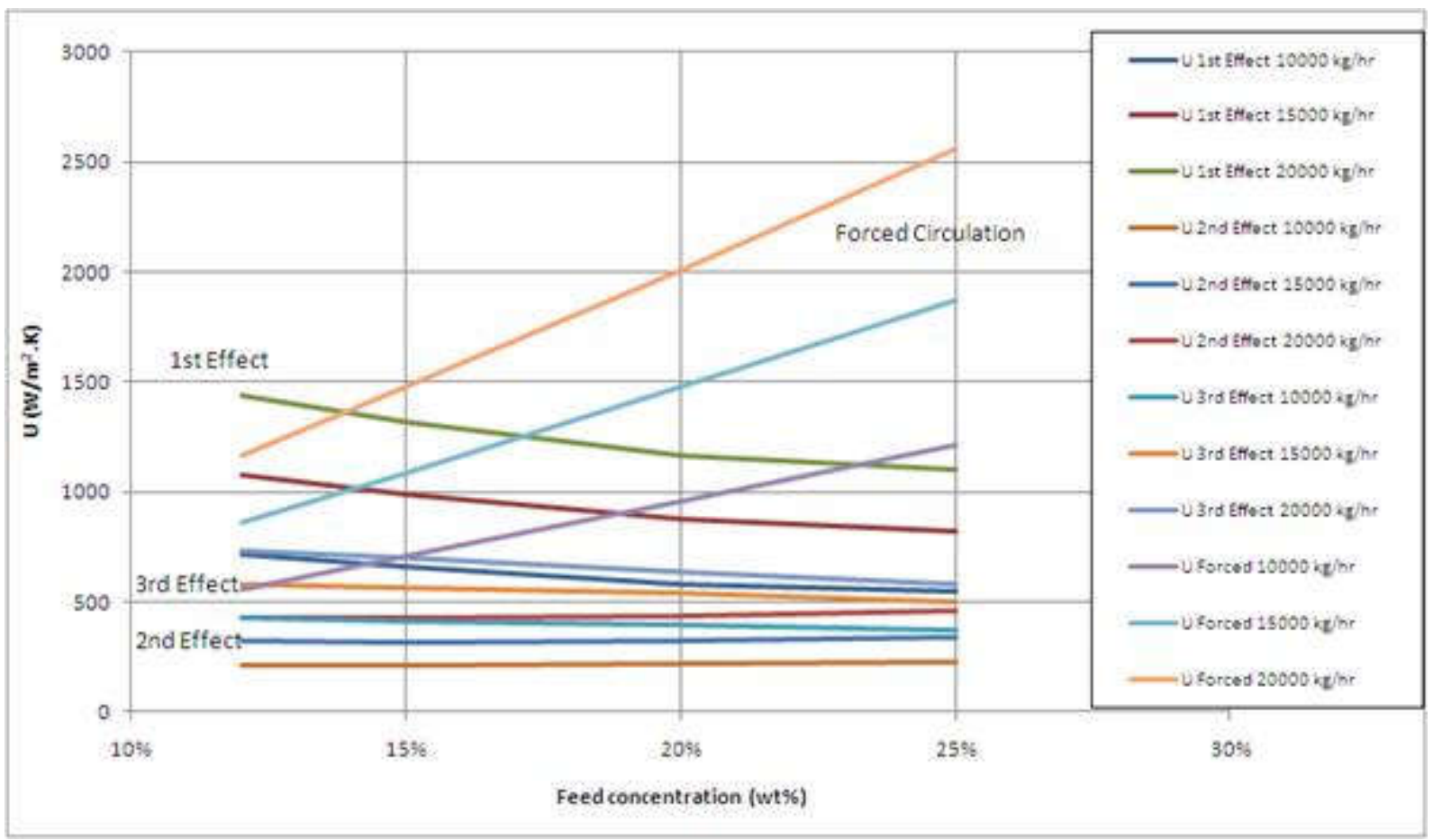

Figure 4. Performance curves of low pressure steam (LPS) and high pressure steam (HPS) requirement 
79 | Indonesian Journal of Science \& Technology, Volume 1 Issue 1, April 2016 Hal 74-81

Figure 5 shows that the preheater 4 can be the bottleneck with the increasing feed concentration. To keep its temperature constraint, more heat needs to be transferred as more HPS is required. Hence, if this temperature constraint needs to be kept, increasing the feed concentration to about $17-18 \mathrm{wt} \%$ at $20.000 \mathrm{~kg} / \mathrm{h}$ of feed may make this preheater a bottleneck.

The same situation also happens with the preheater 1 . This heat exchanger has a constraint to cool the product to maximum $40^{\circ} \mathrm{C}$. With increasing feed concentration, the product flowrate increases. Hence, it requires higher $U$ values. For about $20 w t \%$ of feed concentration and $20.000 \mathrm{~kg} / \mathrm{hr}$ of feed, this preheater may become the bottleneck.

The above bottlenecks observation is depicted in Figure 6. Current situation is at $10.000 \mathrm{~kg} / \mathrm{hr}$ of feed and $12 \mathrm{wt} \%$ feed concentration. By keeping the flowrate constant, increasing the feed concentration to 15 wt\% will make the $4^{\text {th }}$ effect the bottleneck. On the other hand, at the same concentration, increasing the flowrate to below $15.000 \mathrm{~kg} / \mathrm{hr}$ will make the $\mathbf{1}^{\text {st }}$ effect the bottleneck. However, since this unit is at the early step of the process, this impact is barely noticeable in the plant. Its load is shifted to preheater 3 and the $2^{\text {nd }}$ effect, while the condensate load is shifted to preheater 2. At $15000 \mathrm{~kg} / \mathrm{hr}$, both LPS and $4^{\text {th }}$ effect become the bottlenecks. Due to its much smaller area, it is obvious that the $4^{\text {th }}$ effect is the first bottleneck in both situations (increasing feed flowrate or concentration). The estimate of this first bottleneck has been confirmed on the field. Hence, the result of this simulation is reasonably accurate. The remaining bottlenecks can be seen in Figure 6 .

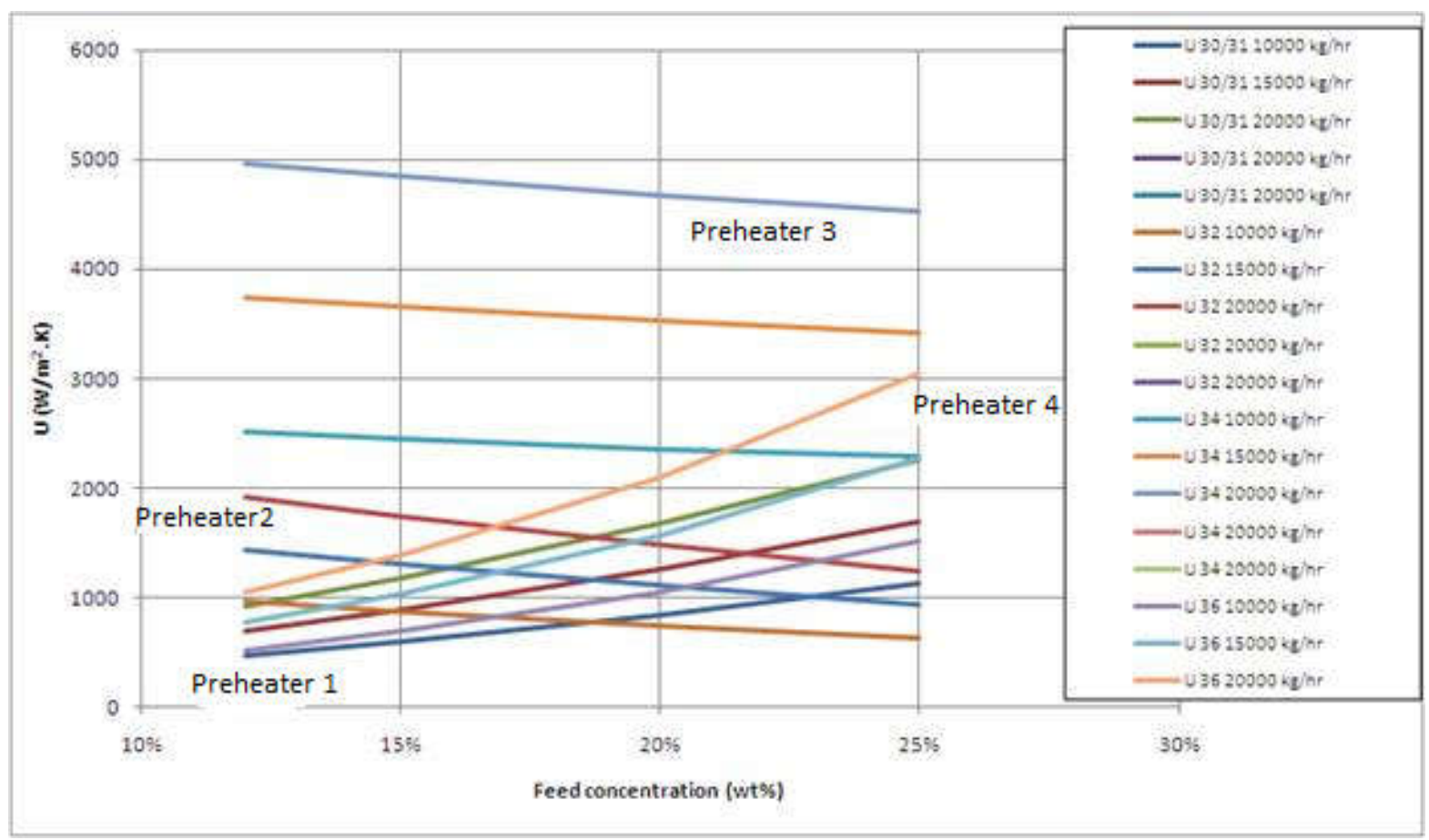

Figure 5. Performance curves of the preheaters 
The total evaporated water in this multiple effect evaporator is simulated by Aspen Plus with the default sequential modular mode. All of the above datasheet information, $U$ values, and operational constraints are taken into account. With this additional information, the simulation can be solved much better. The result is shown in Figure 7, which shows the maximum plant capacity (maximum evaporated water) for different feed concentrations.

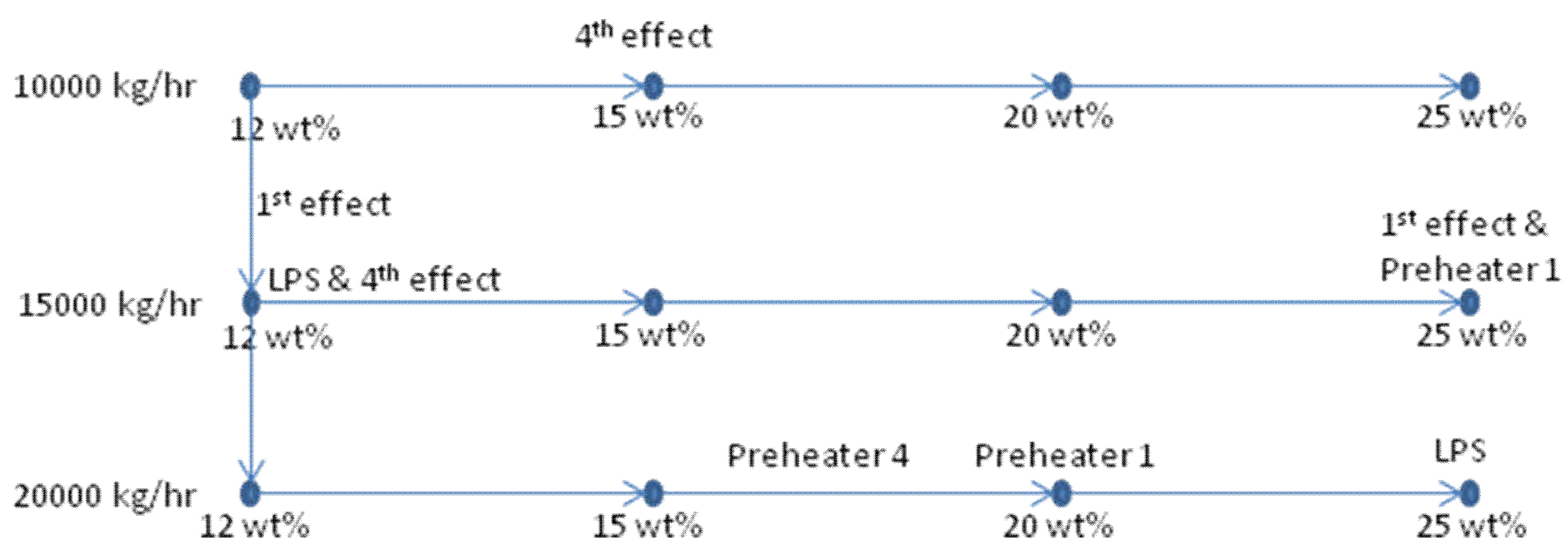

Figure 6. Sequences of bottlenecks

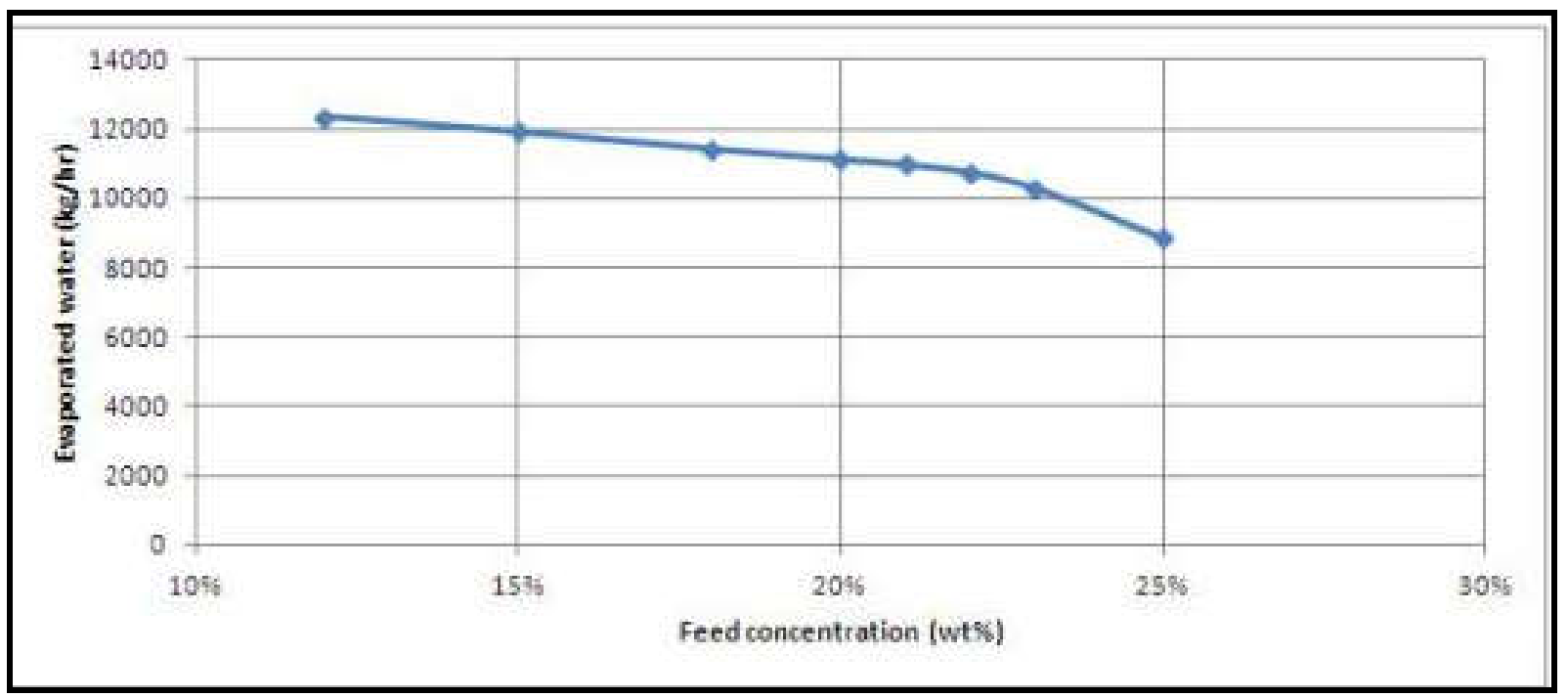

Figure 7. Current capacity limit in evaporating water with varying feed 


\section{CONCLUSIONS}

The approach described in this work has been used to solve an industrial problem. The work requires strong interactions between operational people, consistent data gathering, and process simulation skill. The result has shown that the model can identify, with reasonable accuracy, the first bottleneck as confirmed on the field. Sequence of bottlenecks and their corresponding increment of capacity increase have also been identified. Thus, the

aim of this paper to illustrate the use of process simulation for plant debottlenecking has been achieved.

\section{AUTHOR'S NOTES}

The author(s) declare(s) that there is no conflict of interest regarding the publication of this article. Authors confirmed that the data and the paper are free of plagiarism.

\section{REFERENCES}

Biegler, L. T., Cervantes, A. M., and Wächter, A. (2002). Advances in simultaneous strategies for dynamic process optimization. Chemical Engineering Science, 57(4), 575-593.

Litzen, D. B. and Bravo, J. L. (1999). Uncover low-cost debottlenecking opportunities. Chemical Engineering Progress, 95(3), 25.

Pegels, C. C., and Watrous, C. (2005). Application of the theory of constraints to a bottleneck operation in a manufacturing plant. Journal of Manufacturing Technology Management, 16(3), 302-311.

Skogestad, S. (2004). Control structure design for complete chemical plants. Computers and Chemical Engineering, 28(1), 219-234.

Turton, R., Bailie, R. C., Whiting, W. B., and Shaeiwitz, J. A. (2008). Analysis, synthesis and design of chemical processes. Pearson Education.

Zhu, X. X., and Asante, N. D. K. (1999). Diagnosis and optimization approach for heat exchanger network retrofit. AIChE journal, 45(7), 1488-1503. 